December 2011

\title{
Health Literacy: An overview of an emerging field
}

\author{
Mary Grace Flaherty \\ Syracuse University, mgflaher@syr.edu
}

Follow this and additional works at: https://scholarworks.sjsu.edu/ischoolsrj

Part of the Library and Information Science Commons, and the Medicine and Health Sciences Commons

\section{Recommended Citation}

Flaherty, M. (2011). Health Literacy: An overview of an emerging field. School of Information Student Research Journal, 1(2). https://doi.org/10.31979/2575-2499.010204 Retrieved from https://scholarworks.sjsu.edu/ischoolsrj/vol1/iss2/4

This article is brought to you by the open access Journals at SJSU ScholarWorks. It has been accepted for inclusion in School of Information Student Research Journal by an authorized administrator of SJSU ScholarWorks. For more information, please contact scholarworks@sjsu.edu. 


\section{Health Literacy: An Overview of an Emerging Field}

The field of library and information science has a long history of encouraging lifelong learning and literacy. The public library has been well documented as an educational resource throughout communities in the United States (De la Peña McCook, 2004; Johnson, 1938; Taylor, 2010). Public libraries have a history of offering a variety of programs to promote early literacy and adult literacy, and are now expanding services in some cases to include digital and financial literacy. Another type of literacy or skill set is coming to the forefront and has a significant impact on individuals' lives and well-being: health literacy. Do libraries and librarians have a role to play in this newly emerging field of literacy?

This paper opens with background information and definitions of health literacy. Measurement tools, limited literacy, and implications for quality health care are then explored. A discussion of the role of libraries, future research, and implications of this emergent field of study are also addressed.

\section{Background and Definition}

The field of health literacy is relatively new and as such suffers from a lack of coherent theory or overarching contextual framework. This may not be by chance, as concepts in the area of health literacy span many disciplines, including education, health communication, behavioral science, medicine, linguistics, public health, anthropology, sociology, and psychology. Additionally, the problem of individuals' differing levels of health literacy skills has largely gone unrecognized until fairly recently. The health effects of low literacy and illiteracy have been referred to as "the silent epidemic" (Marcus, 2006, p. 339).

Thus far, health literacy has been studied in the biomedical context, and viewed, for the most part, as a biomedical issue or problem. A number of organizations have sought to define health literacy. In 2009, the Literacy Assistance Center (LAC) collected and published a range of definitions on their website. Their list of definitions was compiled from various sources, including the U.S. Department of Health and Human Services, the American Medical Association (AMA), the Health Literacy Network (Canada), the Office of the Mayor of New York City, and the book, Advancing Health Literacy by Zarcadoolas, Pleasant, and Greer (2006). Commonalities existed among all of the definitions cited. While the posting by the LAC stated that the AMA's definition referred to "a constellation of skills," they stated that academicians Zarcadoolas et al. referred to a "wide range of skills and competencies." The concept of an individual's ability to negotiate within the health care environment was prevalent across all definitions: "ability to perform...tasks to function in the health care environment" (Literacy Assistance Center, 2009). The LAC's post reported the 
Health Literacy Network's definition as including the "ability...to take care of ourselves;" the NYC Mayor's Office of Adult Education as including "take appropriate actions to protect and promote health;" and the book Advancing Health Literacy as including "reduce health risks and increase quality of life" (Literacy Assistance Center, 2009).

Currently, the most widely accepted definition, presented by the National Library of Medicine (Selden, Zorn, Ratzan \& Parker, 2000) and developed by Ratzan and Parker (2000) is, "The degree to which individuals have the capacity to obtain, process, and understand basic health information and services to make appropriate health decisions" (Institute of Medicine, 2004, p. 4). This is the definition adopted for use by the U.S. Department of Health and Human Services for their publication Healthy People 2010. As the field moves toward consensus, this definition has gained more widespread adoption over recent years, and incorporates concepts from the various definitions cited above. The LAC and the AMA now use the Healthy People 2010 definition on their websites, though the AMA has appended the words "and follow instructions for treatment" (American Medical Association, 2011; Literacy Assistance Center, 2011). The definitions cited by the LAC in 2009 on their website no longer appear on any of the cited organizations' websites. Sharing a common definition is one of the first steps in the effort to create a common understanding across disciplines in order to address the challenges associated with health literacy.

According to the Institute of Medicine (IOM, 2004), there are a variety of interwoven factors that can affect health literacy. These include culture, education, language, and the actual health care setting. Additionally, health literacy cannot be studied without also examining the health context. The health context includes government agencies, the media, the marketplace, and the materials and interactions individuals have regarding health. Health literacy is considered to be a "reciprocal function of the health context and the individual" (Institute of Medicine, 2004, p. 66). That is to say that neither the individual nor the health context can be viewed or studied separately when investigating the complex issue of how to address low health literacy. For example, in the context of a stressful medical encounter, even individuals with high levels of literacy may not understand what their health care providers are telling them. The health care environment is a unique setting and can have an impact on individuals' capacities to understand and process information.

The problems associated with low levels of health literacy have a substantial impact on citizens from all segments of society. The most common characteristics associated with lower levels of health literacy are age, education level, and ethnicity (Paasche-Orlow, Parker, Gazmararian, Nielsen-Bohlman, \& Rudd, 2005). Levels of health literacy are not constant across the lifespan, nor are they constant across situations for any given individual. Given that this issue has 
major implications for health care provision, a better understanding of the interaction between health literacy levels and successful navigation through the health care system is imperative.

\section{Measurement Tools}

Currently the two most commonly used tools for measuring or assessing health literacy competency are the Rapid Estimate of Adult Literacy in Medicine (REALM) and the Test of Functional Health Literacy in Adults (TOFHLA) (Davis, et al., 1993; Parker, Baker, \& Williams, 1995). The REALM assessment was designed for ease of use in the clinical setting, as it only takes three minutes to administer and requires very minimal training for personnel. The tool consists of a pronunciation test and medical-word recognition. Because of the pronunciation element in the measure, it is only available in English. The TOFHLA measure is more extensive, and includes a test of reading comprehension and numerical ability. This test was developed in the 1990s and the terms used reflect health care materials commonly used during that time period. Because the TOFHLA was a lengthy tool to administer (taking up to 22 minutes), a shortened version called the S-TOFHLA was developed; it takes about 12 minutes or less to administer (Baker, Williams, Parker, Gazmararian, \& Nurss, 1999).

Among those who believe that screening tools are necessary, there is widespread agreement that better tools are needed. To that end, public health researchers are investigating new approaches to quantifying health literacy levels (Smith, 2009). It is becoming increasingly recognized that one composite measure may be difficult to create, as health literacy is context-based and subject to change among individuals and across situations. A framework or "family" of information is necessary to enable the field to move forward, so efforts should be maintained to identify components that can be measured and addressed (Gazmararian, 2009).

There are some in the field who advocate that the current evidence does not support the need for clinical screening of patient literacy, and that the benefits do not warrant the potential harm to patients in the form of shame and alienation. Rather than relying on screening tools, health care providers should be more attentive to patients and communicate without jargon (Paasche-Orlow \& Wolf, 2007). Additionally, health materials should be easier to read, as this poses no harm and benefits all patients (Pignone, DeWalt, Sheridan, Berkman, \& Lohr, 2005).

Until research can demonstrate that screening benefits patients without causing harm, Paasche-Orlow and Wolf (2007) make three recommendations for dealing with limited health literacy: large provider groups and health plans should find estimates of the prevalence of limited literacy in their areas and respond 
accordingly; clinicians and health care administrators should endeavor to reduce unnecessary complexity in the health care setting; and universal precautions should be adopted to support problem solving and to confirm patients' understanding of self-care activities.

\section{Limited Literacy}

It should be noted that at the heart of the health literacy issue is the greater societal problem of limited literacy. It seems that in their efforts to understand health literacy, health researchers have skipped past the issue of literacy in general, and concentrated efforts on understanding the impact of low health literacy. This is understandable, given that literacy has generally been studied within the context of education, not in the health arena. As the field becomes more robust, with more input from a wider range of disciplines, hopefully a greater understanding of the broader implications of limited literacy will occur.

Pleasant (2009) describes health literacy as a social issue with biomedical implications. He further states that there is a need to distinguish literacy problems from communication issues. This assertion is particularly germane to the health care setting. According to the Office of Management and Budget, in 2002 there were 66 million patient encounters across language barriers (Newman, 2003). This introduces yet another aspect of the health care encounter that can further complicate the assessment of low health literacy in the clinical setting. Until we step back and examine limited literacy in the broader context of its impact on societal equity, and on cultural and health disparities, we will be limiting our understanding of the interaction of literacy and health outcomes.

\section{Implications for Quality Health Care}

The link between low health literacy skills and poor health outcomes has been well established. In a systematic review of the literature, patients with low literacy were found to be 1.5 to 3 times more likely to experience a poor outcome, as determined by measures of morbidity, intermediate disease markers, use of health resources, and general health status (DeWalt, Berkman, Sheridan, Lohr, \& Pignone, 2004). Elderly individuals with lower health literacy comprehension have been found to be more likely to have poorer mental and physical health. Additionally, inadequate health literacy has been linked to higher risk-adjusted rates of cardiovascular death in this population and to an increased risk of hospital admission (Baker et al., 2002; Baker, Parker, \& Williams, 1998; Baker et al., 2007; Wolf, Gazmararian, \& Baker, 2005).

In addition to poor health outcomes, low literacy affects patient compliance and self-care capability. One does not have to search far to find 
examples in the medical literature of the negative effects of inadequate literacy. Low levels of the understanding of chronic diseases such as hypertension and diabetes have been linked to low literacy. In one study, 94\% of patients with diabetes and adequate functional health literacy could identify the symptoms of hypoglycemia compared with $50 \%$ of patients with inadequate literacy (Williams, Baker, Parker, \& Nurss, 1998). Findings such as these are of grave concern, as patients may not understand or appreciate the signs of early disease, and thus may delay care, leading to poorer outcomes and increased costs.

Medical treatment can also be adversely affected. Inadequate literacy has been strongly correlated with improper metered-dose inhaler utilization among asthma patients (Williams, Baker, \& Honig, 1998). Another study found that patients with low literacy were unable to understand prescription drug warning labels (Davis, Wolf, \& Bass, 2006). Preventive care is yet another area that can be adversely affected by low literacy levels. In a study of low-income women in Louisiana, $39 \%$ with a third-grade reading level did not know what a mammogram was for, as compared with only $12 \%$ of women with a reading level at or above the ninth grade level (Davis et al., 1996). It is apparent that inadequate literacy can produce negative effects at all levels of encounters in the patient care process. In addition, as there is an increasing emphasis on patient-centered care, individuals with inadequate literacy levels will not only be left behind, but will face increasing challenges in health care settings.

As the adverse consequences of low literacy with regard to health status become increasingly known, members of the health care community are responding with varied approaches. Many advocate for simplifying print materials for patients (Lee, 1999; Wilson, 2000). This approach is a relatively easy and cost-effective response to initiate. Tailored educational approaches have also been found to help patients to learn and remember self-management skills in asthma treatment, and to improve outcomes for diabetes management (Paasche-Orlow \& Riekert et al., 2005; Rothman et al., 2004).

Organizations across the country are building coalitions and engaging in outreach activities to improve health literacy in their communities (Pomerantz, Muhammad, Downey, \& Kind, 2008). While these efforts are encouraging, there is a need to address low literacy at core levels to address the health disparities in our society. As stated in Eradicating Low Health Literacy, "No one organization can advance health literacy alone" (Pfizer Inc., 2003, p. 16). Partnerships are important because they provide forums for reaching new and larger audiences, sharing resources, creating new tools, expanding services, and increasing funding opportunities (Libraries for the Future, 2009). 


\section{The Role of Libraries}

Librarians are becoming involved in efforts to improve health literacy levels. In her 2009 keynote address at the Libraries for the Future Building Partnerships conference, literacy expert Rudd (2009) stated "Libraries are the only public institution that says to its users: 'we trust you.' The importance of that philosophy in promoting health literacy-particularly among the underserved-cannot be underestimated." Public libraries in particular have been identified as a natural partner in promoting health literacy efforts. This is due to the fact that not only do public libraries provide free and anonymous information to all, but they are also located in almost every neighborhood throughout the country, and are connected to other community resources. Additionally, librarians are trained to aid patrons in finding information. Libraries are gateways to electronic access for the underserved (Libraries for the Future, 2009). Organizations such as the American Library Association (ALA) and the Medical Library Association (MLA) recognize the potential role librarians can play and are involved in efforts to promote health literacy (American Library Association, 2009; Hogan-Smith, 2004).

These efforts include projects such as the Health Information Literacy Research Project, an undertaking by the MLA, funded by the National Library of Medicine to study the role of the librarian as health literacy educator (Shipman \& Funk, 2009). The efforts of the MLA have been primarily geared toward medical libraries and health care settings, not public libraries. The ALA's Reference and User Services Association currently offers a class, Health Information 101, for interested librarians. The class includes six modules, one of which is literacy and health outcomes. These study and training efforts are appropriate steps and indicate recognition, in both the medical library and public library fields, of the importance of engaging in efforts to address health literacy issues and the need for librarians to become involved.

Other avenues for public libraries and librarians to consider may be to offer direct training for patrons and community members on how to find authoritative, high quality health information. Library science programs should adapt to include courses addressing consumer health information and all types of information literacies, including health literacy, in the core curriculum.

It is clear that the notion put forth by physician David Baker a decade ago rings true today: a national effort is necessary to determine what approaches and strategies are effective for communicating health information to patients, no matter what their educational level, reading ability, culture, or language (Baker, 1999). Given the complexity of issues surrounding health literacy, that effort will require collaboration not only across disciplines but across institutions as well. 


\section{Future Research}

As the field of health literacy has become better established, the need for more research has been recognized at the national level. In the American Recovery and Reinvestment Act of 2009, the National Institutes of Health (NIH) included health literacy as one of their highest priority challenge topics. On the NIH website, the request for grant proposals stated: "We propose research that investigates interventions that address health literacy issues (e.g., technology tools, literacy aides or other community health workers, language-appropriate labels for prescription and over-the-counter medications) and their relationship to health outcomes for health disparity populations" (U.S. National Institutes of Health, 2009).

The IOM (2004) has identified a number of areas in which further research is needed. These include the need for causal models explaining the relationships among health literacy, the health system, the education system, and relevant cultural and social systems. The IOM advocates for studies on health service utilization and expenditures and culturally appropriate new measures of health literacy. They also recommend research on the development of conceptual frameworks on the intersection of culture and health literacy. Of interest are the different approaches of these health care agencies. While the NIH is focused on interventions, the IOM is interested in establishing the theoretical underpinnings of the field. It is clear that both approaches are necessary and will need to be addressed in tandem.

\section{Conclusion}

The challenges in the emergent field of health literacy, while daunting, are not insurmountable. When one considers that the first articles on the subject appeared just 20 years ago, it is apparent that strides have been made in the understanding of the interplay between the many factors that affect health literacy. At the heart of the issue are the challenges and problems associated with limited literacy in general, which become acutely manifested in the health care setting. To address these problems, a multidisciplinary approach is coming to the fore. The trend seems to be toward collaboration among a wider range of medical personnel, scholars, and policymakers to coordinate efforts to better understand the underlying issues and to cope with the societal effects of low health literacy. Librarians and information scientists may have a role to play in these collaborative efforts and should be exploring how they might contribute to this emerging field.

There are different viewpoints regarding what the next steps are in the field. According to Weiss (2009), one of the leading experts in the field of health 
literacy, the most important next step is to identify a measure to assess and quantify health literacy levels. The measure must be valid and reliable across time and across different groups. Either the assessment tool needs to be invented or existing tools (such as TOFHLA) need to be validated. In order to answer the question of whether improved health literacy leads to improved health outcomes, it is necessary to be able to quantify and measure health literacy levels (Weiss, 2009). As stated earlier, there are some in the field who disagree with this viewpoint and advocate better patient education materials instead of screening (Paasche-Orlow \& Wolf, 2007). What is important to note is that the discussion is taking place, with many interested parties looking for ways to address this critical cultural and health care issue.

IOM's 2004 report states that, "More needs to be known about the causal pathways between education and health, the role of literacy, and the discrete contribution of health literacy to health" (p. 13). It is clear that a systematic, multidisciplinary approach will be needed to address the complex issue of health literacy. Although the focus in the field thus far has been biomedical in nature, it is time to step back and take a more holistic approach to identify the best approaches to assessment, measurement and intervention. Only then can we reduce the health disparities created by the differing levels of health literacy in our society.

\section{References}

American Library Association. (2009, April 7). Literacy for all: Advocacy, libraries and literacy [Webcast]. Retrieved from www.ala.org/ala/newspresscenter/news/pressreleases2009/march2009/olos literacypanel

American Library Association. (2011). ALA: RUSA online learning offerings. Retrieved from http://www.ala.org/ala/onlinelearning/unit/rusa.cfm

American Medical Association (2009). Health literacy program. Retrieved from http://www.ama-assn.org/ama/pub/about-ama/ama-foundation/ourprograms/public-health/health-literacy-program.page

Baker, D. W. (1999). Reading between the lines, deciphering the connections between literacy and health. Journal of General Internal Medicine, 14, 315-317. 
Baker, D. W., Gazmararian, J. A., Williams M. V., Scott, T., Parker, R. M., Green, D., Ren, J., \& Peel, J. (2002). Functional health literacy and the risk of hospital admission among Medicare managed care enrollees. American Journal of Public Health, 92, 1278-1283.

Baker, D. W., Parker, R. M., \& Williams, M. V. (1998). Health literacy and the risk of hospital admission. Journal of General Internal Medicine, 13, 791798.

Baker, D. W., Williams, M. V., Parker, R. M., Gazmararian, J. A., \& Nurss, J. (1999). Development of a brief test to measure functional health literacy. Patient Education and Counseling, 38, 33-42.

Baker, D. W., Wolf, M. S., Feinglass, J., Thompson, J. A., Gazmararian, J. A., \& Huang, J. (2007). Health literacy and mortality among elderly persons. Archives of Internal Medicine, 167, 1503-1509.

Davis, T. C., Arnold, C., Berkel, H. J., Nandy, I., Jackson, R. H., \& Glass, J. (1996). Knowledge and attitude on screening mammography among lowliterate, low-income women. Cancer, 78, 1912-1920.

Davis, T. C., Long, S. W., Jackson, R. H., Mayeaux, E. J., George, R. B., Murphy, P. W., \& Crouch, M. A. (1993). Rapid estimate of adult literacy in medicine: A shortened screening instrument. Family Medicine, 25, 391395.

Davis, T. C., Wolf, M. S., \& Bass, P. F. (2006). Low literacy impairs comprehension of prescription drug warning labels. Journal of General Internal Medicine, 21, 847-851.

De la Peña McCook, K. (2004). Introduction to public librarianship. New York, NY: Neal-Schuman Publishers.

DeWalt, D. A., Berkman, N. D., Sheridan, S, Lohr, K. N., \& Pignone, M. P. (2004). Literacy and health outcomes. Journal of General Internal Medicine, 19, 1228-1239.

Gazmararian, J.A. (2009, February). America's health insurance plans. In Roundtable on Health Literacy. Symposium conducted at the Institute of Medicine, Washington, D.C. 
Health Literacy Network (2009, March 26). Definition of health literacy. Retrieved from http://www.bccpd.bc.ca/prgograms/wdi/healthliteracynetwork.htm

Helitzer, D., Hollis, C., Cotner, J., \& Oestreicher N. (2009). Health literacy demands of written health information materials: An assessment of cervical cancer prevention materials. Cancer Control, 16, 70-78.

Hogan-Smith, C. (2004). Health literacy and librarians: Raising awareness, sharing solutions. MLA News, 369, 13.

Institute of Medicine of the National Academies (2004). Committee on health literacy, board on neuroscience and behavioral health. In Nielsen-Bohlman L, Panzer A. M., Kindig D. A., (Eds.), Health literacy: A prescription to end confusion. Washington, DC: The National Academies Press.

Johnson, A. (1938). The public library-A people's university. New York: American Association for Adult Education.

Kirsch, I. S., Jungeblut, A., Jenkins, I., \& Kolstad, A. (1993). Adult literacy in America: A first look at the results of the National Adult Literacy Survey (NALS). Washington, DC: National Center for Education Statistics, U.S. Department of Education.

Lee, P. P. (1999). Why literacy matters. Archives of Ophthalmology, 117, 100103.

Libraries for the Future. (2009). Health literacy basics. Retrieved from http://www.lff.org/ffl/healthliteracy.rtf

Literacy Assistance Center. (2009). Definition of health literacy. Retrieved from http://www.lacnyc.org/resources/healthlit/definition.htm

Literacy Assistance Center. (2011). Definition of literacy. Retrieved from http://lacnyc.org

Marcus, E. N. (2006). The silent epidemic-The health effects of illiteracy. New England Journal of Medicine, 355, 339-341.

Newman, B. (2003, January 9). Doctors' orders can get lost in translation for immigrants. The Wall Street Journal, p.1. 
New York City Mayor's Office of Adult Education (2009). Health literacy. Retrieved from http://www.nyc.gov/html/adulted/downloads/pdf/fellowship_brochure_20 09.pdf

Paasche-Orlow, M. K., Parker, R. M., Gazmararian, J. A., Nielsen-Bohlman, N. T., \& Rudd, R. R. (2005). The prevalence of limited health literacy. Journal of General Internal Medicine, 20, 175-184.

Paasche-Orlow, M. K., Riekert, K. A., Bilderback, A., Chanmugam, A., Hill, P., Rand, C. S., Brancati, F. L., \& Krishnan, J. A. (2005). Tailored education may reduce health literacy disparities in asthma self-management. American Journal of Respiratory Critical Care Medicine, 172, 980-986.

Paasche-Orlow, M. K., \& Wolf, M. S. (2007). Evidence does not support clinical screening of literacy. Journal of General Internal Medicine, 23, 100-102.

Parker, R. M., Baker, D. W., \& Williams, M. V. (1995). The Test of Functional Health Literacy in Adults (TOFHLA): A new instrument for measuring patients' literacy skills. Journal of General Internal Medicine, 10, 537542.

Pfizer Inc. (2003, March). Eradicating low health literacy: The first public health movement of the $21^{\text {st }}$ century [White Paper]. New York, NY: Partnership for Clear Health Communication Steering Committee.

Pignone, M., DeWalt, D. A., Sheridan, S., Berkman, N., \& Lohr, K. N. (2005). Interventions to improve health outcomes for patients with low literacy: A systematic review. Journal of General Internal Medicine, 20, 185-192.

Pleasant, A. (2009, February). Health literacy measures-The positives and negatives of a wide range of tools. In Roundtable on Health Literacy. Symposium conducted at the Institute of Medicine, Washington, DC.

Pomerantz, K. L., Muhammad, A. A., Downey, S., \& Kind, T. (2010). Connecting for health literacy: Health information partners. Health Promotion Practice, 11, 79-88.

Ratzan, S. C. \& Parker, R. M. (2000). Introduction. In Selden, C. R., Zorn, M., Ratzan, S. C., \& Parker, R. M. (Eds.), National Library of Medicine current bibliographies in medicine: Health literacy. NLM Pub. No. CBM 
2000-1. Bethesda, MD: National Institutes of Health, U.S. Department of Health and Human Services.

Rothman, R. L., DeWalt, D. A., Malone, R., Bryant, B., Shintani, A., Crigler, B., Weinberger, M., \& Pignone, M. (2004). Influence of patient literacy on the effectiveness of a primary care-based diabetes disease management program. Journal of the American Medical Association, 92, 1711-1715.

Rudd, R. R. (2009). Libraries for the future. Building partnerships [Keynote address]. Retrieved from http://www.actforlibraries.org/old\%20site/pdfs/Portrait_HealthAccess.pdf

Selden, C. R., Zorn, M., Ratzan, S. C., \& Parker, R. M. (2000). National Library of Medicine current bibliographies in medicine: Health literacy. NLM Pub. No. CBM 2000-1. Bethesda, MD: National Institutes of Health, U.S. Department of Health and Human Services.

Shipman, J. P., \& Funk, C. J. (2009). Teachers of health information literacyFuture roles for librarians. IFLA Proceedings, $75^{\text {th }}$ IFLA General Conference and Council.

Smith, S. (2009, February). A functional approach to assessing health literacy. In Roundtable on Health Literacy. Symposium conducted at the Institute of Medicine, Washington, DC.

Taylor, E. W. (2010). Cultural institutions and adult education. New Directions for Adult and Continuing Education, 127, 5-14.

U.S. Department of Health and Human Services (DHHS) (2000). Healthy People 2010: Understanding and improving health. Washington, DC: U.S. Department of Health and Human Services.

U.S. National Institutes of Health. (2009). Challenge grant applications. Retrieved from http://grants.nih.gov/grants/funding/challenge_award/Omnibus.pdf

Weiss, B. (2009, February). Commentary. In Roundtable on Health Literacy 7. Symposium conducted at the Institute of Medicine, Washington, DC.

Williams, M. V., Baker, D. W., \& Honig, E. G. (1998). Inadequate literacy is a barrier to asthma knowledge and self-care. Chest, 114, 1008-1015. 
Williams, M. V., Baker, D. W., Parker, R. M., \& Nurss, J. R. (1998). Relationship of functional health literacy to patients' knowledge of their chronic disease. Archives of Internal Medicine, 158, 166-172.

Wilson, F. L. (2000). Are patient information materials too difficult to read? Home Healthcare Nurse, 18, 107-115.

Wolf, M. S., Gazmararian, J. A., \& Baker, D. W. (2005). Health literacy and functional health status among older adults. Archives of Internal Medicine, 165, 1946-1952.

Zarcadoolas, C., Pleasant, A., \& Greer, D. S. (2006). Advancing health literacy: A framework for understanding and action. Hoboken, NJ: Jossey-Bass. 